\title{
AS POTENCIALIDADES DO AMBIENTE VIRTUAL DE APRENDIZAGEM NO CURSO DE ENFERMAGEM: A CONCEPÇÃO DOCENTE
}

\author{
Amanda Delibório, Adriana Aparecida de Lima Terçariol \\ Universidade do Oeste Paulista - UNOESTE, Mestrado em Educação, Presidente Prudente, SP. E-mail: \\ amandadeliborio@gmail.com.
}

\section{RESUMO}

O presente estudo é recorte da pesquisa desenvolvida no Programa de Mestrado em Educação da Universidade do Oeste Paulista e tem como objetivo geral apresentar e discutir algumas potencialidades do Ambiente Virtual de Aprendizagem (AVA) e seus recursos às práticas pedagógicas dos professores que atuam no ensino superior, especialmente, no curso de Enfermagem. A pesquisa assumiu caráter qualitativo, do tipo estudo de caso. Os participantes da pesquisa foram 12 docentes atuantes no curso de Enfermagem de uma Instituição de Ensino Superior Privada de Presidente Prudente/SP e que utilizam o AVA em suas disciplinas. Para a obtenção dos dados foram realizadas entrevistas semiestruturadas. Os dados da entrevista foram organizados e analisados, por meio da técnica do Discurso do Sujeito Coletivo (DSC). Aqui neste artigo apresentam-se recortes dos textos organizados a partir dessa técnica, com o intuito de evidenciar as potencialidades do AVA e alguns de seus recursos, evidenciando-se assim as percepções dos docentes, sujeitos desta pesquisa. Os principais resultados evidenciaram que o AVA potencializa a prática docente e contribui para a melhoria no processo ensino e aprendizagem dos acadêmicos de Enfermagem.

Palavras-chave: Tecnologias da Informação e Comunicação, Ambientes Virtuais de Aprendizagem, Ensino e Aprendizagem, Práticas Pedagógicas, Ação Docente.

\section{THE CAPABILITIES OF THE VIRTUAL LEARNING ENVIRONMENT IN NURSING COURSE: THE TEACHER CONCEPTION}

\begin{abstract}
This study is the snip of the research developed in the Master's Education Program from the University of West Paulista, it presents as a general objective to understand how the potential present in the Virtual Learning Environment (VLE) and its resources can be linked to the pedagogical practices of teachers who work in higher education in the nursing course. The research took on a qualitative approach of the case study. The participants of the research were acting 12 teachers in the nursing course from a private Higher Education Institution of Presidente Prudente / SP and that use the AVA in their disciplines. To obtain the data semi-structured interviews were conducted. The interview data were organized and analyzed, through the Collective Subject Speech (CSS). The main results showed that the AVA enhances teaching practice and contributes to the improvement in the teaching and learning of nursing students.

Keywords: Information and Communication Technologies, Virtual Learning Environments, Teaching and Learning, Pedagogical Practices, teaching activities
\end{abstract}




\section{INTRODUÇÃO}

Os ambientes virtuais são espaços de ensino e aprendizagem com o apoio da Internet que possibilitam o desenvolvimento de atividades no tempo, espaço e ritmo de cada participante. Os AVA podem ser usados de várias formas, como, por exemplo: em atividades presenciais, possibilitando transcender as interações para além da sala de aula; em atividades semipresenciais, e também a distância (RIBEIRO; MENDONÇA; MENDONÇA, 2007). Neste sentido, os AVA favorecem novas dinâmicas para o processo de ensino e de aprendizagem. (FERREIRA, 2014).

O AVA abrange interfaces instrucionais e contribui para que o estudante tenha acesso aos materiais didáticos do curso/disciplina, bem como interaja com os colegas de turma e com o professor. Disponibiliza recursos para auxiliar nas aprendizagens individual e coletiva, permitindo a integração de diferentes mídias e formatos. Dentre os recursos existentes, na maioria dos ambientes virtuais, tem-se: textos, hipertextos, sons, imagens e vídeos. Como recursos de comunicação, destacam-se: bate-papo, fóruns de discussões, correio eletrônico, e outros que permitem a interação entre os participantes de um processo de formação (ALMEIDA, 2003).

A utilização dos AVA na Enfermagem é uma alternativa pedagógica bastante favorável e interessante. Esses ambientes propiciam a estruturação do conhecimento, a partir da aprendizagem colaborativa e apresentam relevantes elementos informacionais, comunicacionais, tecnológicos, projetados para dar suporte a processos interativos. Essa potencialidade que o AVA oferece vai ao encontro do que Moran defende em termos de educação. Segundo esse autor, devemos "educar para saber compreender, sentir, comunicar-se e agir melhor, integrando a comunicação pessoal, a comunitária e a tecnológica." (MORAN, 1997, p.7).

Os recursos presentes no ambiente virtual propiciam as interações, como as trocas individuais e a formação de grupos colaborativos. Os estudantes discutem algumas questões e temas de interesses comuns, pesquisam e criam (ALMEIDA, 2001). No ambiente virtual, o estudante se encontra livre para expor suas opiniões, discute questões pertinentes que envolvem o conteúdo exposto, participa de processos interativos como a troca de informações, dentre outras ações.

Quanto ao docente, trabalhar com ambientes virtuais de aprendizagem requer a estruturação de situações de aprendizagem, planejar e propor atividades, disponibilizar materiais de apoio, usando diversas mídias e linguagens. Cabe ao professor ser mediador e orientar o estudante, procurando identificar suas dúvidas e dificuldades, bem como disponibilizar informações relevantes e claras, instigar o estudante a buscar e propiciar a reflexão sobre os processos de ensino (ALMEIDA, 2003). A utilização de novos dispositivos a distância, como os AVA, pode propiciar a reconstrução do papel do professor, a reflexão de sua ação e suas práticas docentes. Além disso, permite que o professor rompa com barreiras temporais e espaciais e adentre em um novo universo educacional. Todavia, para que o docente desenvolva habilidades a partir da inserção das tecnologias na educação, o mesmo precisa se atualizar, aprender sobre a utilização de novas metodologias de ensino.

É nesta perspectiva desafiadora que se revela a área de educação em Enfermagem, diante dos avanços das tecnologias de informação e comunicação nos espaços acadêmicos. Esse enfoque incita os educadores a conhecerem, analisarem e transformarem essas novas tecnologias em um instrumento educacional articulado às condições políticas, econômicas, sociais e culturais nas quais o ensino se insere, bem como atenderem às demandas de uma clientela universitária considerada como uma geração digital.

Portanto, frente a essa nova modalidade educacional e a esse novo perfil de estudante, faz-se necessário compreender as potencialidades dos recursos existentes no AVA e como esses podem possibilitar mudanças no perfil dos professores e dos estudantes de Enfermagem, bem como auxiliar no ensino e aprendizado desses estudantes. Nesse sentido, como objetivo geral o 
presente estudo pretende elucidar as potencialidades do AVA e alguns de seus recursos, evidenciando-se assim as percepções dos docentes, sujeitos desta pesquisa.

\section{METODOLOGIA}

A pesquisa desenvolvida assumiu uma abordagem qualitativa, uma vez que ela ofereceu alternativas para o desenvolvimento e a compreensão das relações entre os fatores sociais e sua situação, como também uma compreensão detalhada das crenças, atitudes, valores e motivações em relação aos comportamentos das pessoas, em contextos específicos (BAUER; GASKEL, 2007).

Nessa perspectiva a pesquisa contou como contexto um curso de graduação em Enfermagem, ofertado por uma Instituição de Ensino Superior (IES), da rede privada, situada em Presidente Prudente/SP. Como sujeitos da pesquisa, participaram 12 professores do curso de Enfermagem desta referida IES que utilizavam o AVA em suas disciplinas.

A entrevista semiestruturada foi adotada como o instrumento para coleta dos dados. Os dados da entrevista foram organizados e analisados a partir do Discurso do Sujeito Coletivo (DSC) - técnica de análise qualitativa de natureza verbal que é obtida por depoimentos (LEFÈVRE; LEFÈVRE, 2005). A seguir são apresentados apenas alguns trechos das falas dos sujeitos extraídos dos textos que compõem os Discursos do Sujeito Coletivo (DSCs) organizados para algumas das categorias de análise contempladas na pesquisa. Traz-se junto a esses trechos uma breve discussão articulada aos fundamentos teóricos adotados na pesquisa.

\section{RESULTADOS E DISCUSSÃO}

Conforme os dados coletados verificou-se que todos os docentes utilizam o AVA como repositório de materiais de apoio, por meio da ferramenta "envio de arquivo". Desta forma, são anexados roteiros de aulas e materiais didáticos, como artigos e bibliografias, vídeos, textos, documentos para estágios, atividades que ficam disponíveis para que o estudante tenha acesso dentro do ambiente virtual. Conforme se evidencia no trecho do discurso abaixo, extraído do Discurso da Categoria "AVA e seus recursos":

e a questão do uso de imagens, que no Aprender eu costumava usar bastante com o estudante, um vídeo, por exemplo, então isso facilitava o aprendizado. Nesse semestre, eu devo ter usado o Aprender umas três vezes, que foi nos trabalhos em especial de sala de espera. Eu uso o envio de arquivos para o módulo, eu gosto dele. Trecho do DSC-O AVA e seus recursos.

O trecho exposto acima explicita que o AVA é amplamente utilizado pelos professores como repositório de materiais de apoio, e incluem materiais como: textos, leituras complementares, vídeos, atividades ou exercícios, estudos dirigidos, roteiros de estudos, inclusive o roteiro da própria aula em Power Point é disponibilizado para o estudante, de modo a facilitar a compreensão do conteúdo e seu aprendizado. Desta forma, o material didático desempenha um papel de mediador entre o conteúdo e os estudantes, o que favorece o processo de ensino e aprendizagem (SALES, 2005).

Outra forma de utilização do AVA pelos investigados é como meio de interação. O fórum de discussão, deste modo, é um recurso bastante explorado pelos docentes e destaca-se como uma ferramenta que propicia o diálogo, as trocas, a colaboração, como exposto no trecho retirado do Discurso da Categoria A:

[...] eu gosto muito do fórum, porque os estudantes vão interagindo entre eles e vão interagindo comigo também, então a resposta fica mais rápida. $\mathrm{E}$, assim, eu vou conduzindo, e utilizo o fórum para discussões. Trecho do DSC-O AVA e seus recursos. 
Nota-se que o fórum de discussão é um recurso disponível no AVA e que os professores investigados optam por adotá-lo como uma ferramenta de uso em suas disciplinas, por constatarem que, a partir de discussões e temas lançados nesse recurso, constrói-se uma maior relação de interação e colaboração entre os participantes. Conforme Pereira e Giani (2009), o fórum possibilita discussões por meio de mensagens postadas durante um determinado período de tempo que é estabelecido pelo professor/tutor.

Em face disso, o fórum se torna, no contexto do AVA, um recurso que possibilita a comunicação assíncrona e a interação entre os sujeitos envolvidos no processo de ensino e aprendizagem. Os docentes lançam questionamentos ou temas a serem discutidos e relatados pelos participantes diante de algumas questões práticas ou teóricas de determinada disciplina. É nesse momento de compartilhamento que existe a reflexão, tanto dos estudantes diante das situações vivenciadas, como também do professor diante dos posicionamentos emitidos que passam a ser analisados e socializados a todos os participantes. Nessa perspectiva, o fórum desencadeia um processo de reflexão.

A contribuição do uso do fórum no processo ensino e aprendizado é evidenciado, como demonstra o trecho do discurso abaixo:

Eu acredito que poder trocar as informações pelo "Aprender" possibilita uma aproximação mesmo que não física, mas de ensino, uma interação com o estudante. E outra coisa [...], a troca de falas deles nos fóruns, a inter-relação que eles fazem, a agilidade no processo, tanto deles pra mim, como o feedback. Trecho do DSC-O AVA e seus recursos.

Na educação online, o trabalho colaborativo é um fator intrínseco para o ensino e a aprendizagem. Nos contextos virtuais com o uso do AVA, posicionar o estudante como centro da aprendizagem em um processo de cooperação/troca com os demais envolvidos, ou seja, outros estudantes e professores é de fundamental importância.

Percebe-se, ainda, pelas falas dos docentes, que a utilização de alguns recursos no AVA propicia maior interação deles com os estudantes e, também, uma maior proximidade. Quando há interação, subentende-se que precisa existir uma resposta do outro. Ao utilizar o ambiente virtual de aprendizagem, por exemplo, o estudante também espera algum retorno. Para Bordenave $(1982$, p.36), "sem a comunicação cada pessoa seria um mundo em si mesmo, já que é por meio dela que as pessoas compartilham experiências interdependentes, influenciam-se mutuamente e, juntas, modificam a realidade onde estão inseridas".

A utilização do AVA pelos docentes como meio de comunicação, ocorre por meio da ferramenta envio de mensagens. Com o uso dessa ferramenta, os professores se comunicam com os estudantes, como se observa no excerto abaixo:

E eu utilizo o Aprender assim bastante pra enviar mensagens para os estudantes, aí não como ferramenta de ensino, mas como comunicação [...] e a gente se comunica por ali. Trecho do DSC-O AVA e seus recursos.

Ainda por meio do recurso Texto Breve, os docentes se comunicam com os estudantes, enviam recados, informações a respeito das aulas e atividades, como demonstra o trecho do discurso abaixo:

Eu também gosto do texto breve. O texto breve eu uso bastante pra recados, por exemplo, hoje à noite eu preciso postar um texto pra eles de que amanhã não tem monitoria, pra recados rápidos mesmo, alguma coisa de que mudou o horário, então eu gosto bastante do texto breve. Trecho do DSC - O AVA e seus recursos. 
Ao analisar o trecho acima, constata-se que o uso da troca de mensagens facilita a comunicação dos professores com seus estudantes. É importante pontuar que nessa ferramenta o professor não exerce interferência sobre o conteúdo das mensagens trocadas, apenas posta as mensagens que deseja para se comunicar com os estudantes de forma mais rápida.

Além do envio de mensagens, o chat também é uma ferramenta que os professores utilizam como meio de comunicação, que acontece de forma síncrona, ou seja, em tempo real. Ademais, propicia discussões interativas entre dois ou mais participantes ao mesmo tempo. No chat- também conhecido como bate-papo - são trocadas informações e dúvidas dos estudantes com os professores, o que favorece o diálogo. Conforme Mengalli (2006, p. 33), esse recurso também "pode ser utilizado para a aplicação de conceitos necessários à aprendizagem e colaboração síncrona no exercício de atividades, de resolução de problemas ou tomada de decisões rápidas".

Eu gosto mais do chat, são os textos breves, [...] eu faço toda minha comunicação com ele pelo "Aprender". Trecho do DSC-O AVA e seus recursos.

Outra forma da utilização do AVA exposto pelos docentes é que os mesmos utilizam o ambiente como ferramenta de disponibilização de produções dos estudantes e avaliação. Os recursos utilizados pelos professores com essa finalidade são: o questionário, o Trabalho Orientado (Portfólio) e o Diário de Bordo. O questionário é uma ferramenta que avalia o estudante por meio de pontuação que ocorre diante das questões postadas e suas respostas, assim como evidencia o trecho do DSC abaixo:

Eu já utilizei o questionário, então em semanas que antecedem as provas, eu dou o questionário como uma revisão de prova. [...]. Trecho do DSC- O AVA e seus recursos.

A fala exposta demonstra a utilização desse recurso como uma maneira mais prática de avaliar o estudante e seu aprendizado diante de determinado conteúdo.

O trabalho orientado (Portfólio) também é um recurso avaliativo e, ao mesmo tempo, demonstra o feedback dos estudantes diante de algumas situações vivenciadas na prática acadêmica, no campo de estágio. Com essa ferramenta, o professor consegue trabalhar aspectos interpretativos do estudante no que se refere a alguns textos postados, e ainda possibilita instigar o pensamento reflexivo desse estudante, como se observa no excerto do discurso da categoria $A$ abaixo:

[...] então o que eu tenho acessado agora tem sido o trabalho orientado, uma síntese reflexiva de um texto, ou, por exemplo, a produção de portfólio crítico reflexivo. Mas ainda eu o utilizo em algumas situações como portfólio e reflexão de alguns textos. Trecho do DSC - O AVA e seus recursos.

Por meio do portfólio, o estudante também é avaliado pelo professor, pois é nesse recurso que o estudante posta seus trabalhos realizados ou parte deles durante o curso. De maneira geral, utiliza-se essa ferramenta com o objetivo de analisar a evolução do estudante, uma vez que nele pode-se ter textos e outros materiais produzidos em todas as fases do curso (CORRÊA, 2007).

A fala seguinte também explicita a utilização do recurso "Trabalho Orientado", porém com outra perspectiva, o professor dá um feedback ao estudante diante de questões e situações vivenciadas na prática de enfermagem.

Eu esqueci até de citar: a gente utiliza o Aprender com o trabalho orientado que é para a produção de trabalhos de sala de espera em saúde 
da família, então o estudante posta e a gente consegue de forma bem rápida dar uma devolutiva [...] Trecho do DSC-O AVA e seus recursos.

Sendo assim, o recurso trabalho orientado propõe a efetivação de propostas educativas e orientações pertinentes à saúde em ambientes como salas de espera de Unidades Básicas de Saúde. Os estudantes postam no AVA projetos educativos de modo a orientar os usuários da saúde pública sobre determinadas doenças e suas formas de prevenção, bem como outros assuntos pertinentes àquela realidade vivenciada pelo estudante na prática acadêmica.

\section{CONSIDERAÇÕES FINAIS}

As tecnologias digitais juntamente com internet fizeram emergir um novo paradigma social e educacional. Nesse cenário, as tecnologias se inserem nos espaços de aprendizagem e a sala de aula propriamente dita deixa de ser o único espaço para o aprendizado.

Assim, a tecnologia aplicada ao ensino amplia os espaços de aprendizagem, oferecendo acesso a diversos objetos de aprendizagem. Por meio dos ambientes virtuais, pode-se lançar mão de novas metodologias, inovando, auxiliando e favorecendo o trabalho docente bem como o aprendizado dos estudantes.

As diversas ferramentas presentes no AVA detêm suas potencialidades que precisam ser exploradas, contudo, para a utilização do AVA se torne um recurso utilizável de maneira efetiva, é necessário que haja uma reflexão dos docentes, a cerca de suas as ações e de suas práticas, enquanto formadores de futuros profissionais e cidadãos.

\section{REFERÊNCIAS}

ALMEIDA, M. E. B. Educação a Distância na Internet: abordagens e contribuições dos ambientes virtuais de aprendizagem. Educação e Pesquisa, São Paulo, v. 29, n. 2, p 327-340, dez. 2003. https://doi.org/10.1590/s1517-97022003000200010

. Formando professores para atuar em ambientes virtuais de aprendizagem. In: ALMEIDA, F.J. (coord.). Projeto Nave. Educação a distância: formação de professores em ambientes virtuais e colaborativos de aprendizagem. São Paulo: 2001.

BAUER, M.W.; GASKEL, G. Pesquisa qualitativa com texto, Imagem e som: um manual prático. 6.ed. Petrópolis: Vozes, 2007.

BORDENAVE, J. E.D. O que é comunicação. São Paulo: Brasiliense, 1982.

CORRÊA, J. Educação a Distância: orientações metodológicas. Porto Alegre: Artmed, 2007.

FERREIRA, J. L.Moodle: um espaço de interação e aprendizagem. In: COSTA, M. L. F.; ZANATTA, R. M. (Orgs.). Educação a Distância no Brasil: aspectos históricos, legais, políticos e metodológicos. 3. ed. Maringá: Eduem, 2014. p.51-65.

LEFÈVRE, F.; LEFÈVRE, A. M. C. Depoimentos e discursos: uma proposta de análise em pesquisa social. Brasília: Líber Livro, 2005.

MORAN, J. M. A educação que desejamos: novos desafios e como chegar lá. Campinas: Papirus, 2007. 
PEREIRA, J. B.; GIANI, R. C. Avaliação da Aprendizagem em cursos superiores a distância e o sistema de gerenciamento Moodle. In: COSTA, M. L. F. (Org.). Introdução a Educação a Distância. Maringá: Eduem, 2009.

RIBEIRO, E. N.; MENDONÇA, G. A. A.; MENDONÇA, A. F. A importância dos ambientes virtuais de aprendizagem na busca de novos domínios da EAD. 2007. Disponível em:

<http://www.abed.org.br/congresso2007/tc/4162007104526am.pdf>. Acesso em: 5 ago. 2015.

SALES, M. V. S. Uma reflexão sobre a produção do material didático. In: CONGRESSO

INTERNACIONAL ABED DE EDUCAÇÃO A DISTÂNCIA,12., 2005, Florianópolis. Anais... Florianópolis:

Abed, 2005. 